\title{
A linguagem poética e a criança: ouvir, ler, criar, fruir e brincar
}

\author{
Poetic language and the child: listen, read, create, enjoy and play
}

\section{Rosilene de Fátima Koscianski da Silveira}

Universidade Federal de Santa Catarina - UFSC - Santa Catarina - Brasil

\section{Eliane Santana Dias Debus}

Universidade Federal de Santa Catarina - UFSC - Santa Catarina - Brasil

\section{Fernando José Fraga de Azevedo}

Universidade do Minho, Centro de Investigação em Estudos da Criança, Instituto de Educação, Campus de Gualtar - Braga - Portugal

Resumo: A palavra poética, aqui compreendida como dialógica - numa concepção bakhtiniana de linguagem -, mostra-se com duas faces: procede de alguém e se direciona a alguém. É ela que nos possibilita apresentar neste texto os encontros "poesia e criança" vivenciados e refletir acerca dos aspectos que consideramos mais relevantes das interações estabelecidas entre ambas. O artigo reúne parte de investigação de Doutorado em Educação cuja pesquisa de campo propiciou encontros poéticos com crianças em uma escola da rede pública estadual de Criciúma-SC. Neles, foi possível observar a forma pela qual as crianças acolhem, dispensam atenção e interagem com os poemas a elas apresentados, ou por elas trazidos e compartilhados. A metodologia utilizada é denominada "espaços de narrativa" (LEITE, 2008), caracterizada pela realização de encontros sistematizados entre observador e sujeitos, empregando estratégias de natureza etnográfica e uso de diferentes instrumentos para captura de dados, especialmente gravação em vídeo. As palavras sobre poesia e as palavras poéticas lidas, ouvidas, fruídas e/ou inventadas nos encontros abrem um espaço-tempo reflexivo que ajuda a pensar algumas questões: o que as crianças entendem por poesia? Elas apreciam poesia? As crianças têm um acervo poético? Como lidamos com a poesia que as crianças nos apresentam? Como abordar a linguagem poética com crianças no campo da pesquisa e no espaço da escola? A problematização da temática se faz com interlocutores dos campos da linguagem, da literatura, em especial da poesia, da educação e da infância, como Bakhtin (2011), Benjamin (2002, 2013), Vigotski (2009), Paz (2012) e Kirinus (2008).

Palavras-chave: Palavra. Poesia. Poema. Infância. Criança.

Abstract: The poetic word, understood here as dialogical - in a Bakhtinian conception of language -, shows itself with two faces: it comes from someone and it is directed towards someone. It is what enables us to present in this text the experiences "poetry and children" experienced and reflect on the aspects that we consider most relevant in the interactions established between both. The article brings together a part of the Ph.D. research in Education whose field research provided poetic encounters with children at a public school in the state of Criciúma-SC. In them, it was possible to observe the way in which children welcome, pay attention and interact with the poems presented to them, or brought and shared by them. The methodology used is called "narrative spaces" (LEITE, 2008), characterized by the realization of systematic meetings between the observer and the subjects, employing strategies of an ethnographic nature and the use of different instruments for data capture, especially video recording. The words about poetry and the poetic words read, heard, enjoyed 
SILVEIRA, Rosilene; DEBUS, Eliane; AZEVEDO, Fernando de

and / or invented in the meetings open a reflective space-time that helps to think about some questions: what do children understand by poetry? Do they appreciate poetry? Do children have a poetic collection? How do we deal with the poetry that children present to us? How to approach poetic language with children in the field of research and in the school space? The issue is problematized with interlocutors in the fields of language, literature, especially poetry, education and childhood, such as Bakhtin (2011), Benjamin (2002, 2013), Vigotski (2009), Paz (2012) and Kirinus (2008).

Keywords: Word. Poetry. Poem. Childhood. Kid.

\section{Introdução}

A palavra poética, aqui compreendida como dialógica - numa concepção bakhtiniana de linguagem -, mostra-se com duas faces: procede de alguém e se direciona a alguém. Ela está carregada de verdades e mentiras, de coisas triviais, agradáveis ou desagradáveis, de conteúdo ideológico ou vivencial, cuja construção histórica é produzida por sujeitos sociais. É ela - a palavra - que nos possibilita apresentar os encontros "poesia e criança" vivenciados e refletir acerca dos aspectos que consideramos mais relevantes. Com o texto intitulado "A linguagem poética e a criança: ouvir, ler, criar, fruir e brincar" tratamos do encontro poesia e criança e das interações estabelecidas entre ambas. Seu conteúdo é parte de uma pesquisa de Doutorado em Educação que investigou a relação infância e poesia ouvindo, registrando e buscando compreender o diálogo que as crianças estabelecem com a linguagem poética na roda da empiria. Com os encontros poéticos foi possível observar a forma pela qual as crianças acolhem, a atenção que dispensam e o modo como interagem com os poemas a elas apresentados, ou por elas trazidos e compartilhados.

A referida pesquisa foi realizada numa escola da rede pública estadual de Criciúma, cidade de Santa Catarina, sul do Brasil. A metodologia utilizada é denominada "espaços de narrativa" (LEITE, 2008), procedimento caracterizado pela realização de encontros sistematizados entre observador e sujeitos, empregando estratégias de natureza etnográfica e 0 uso de diferentes instrumentos para captura de dados, especialmente a gravação em vídeo. A recolha dos dados ocorreu entre outubro de 2013 e junho de 2014 e contou com a participação de vinte crianças e cinco adultos. Este texto se detém nas contribuições das crianças, oito meninos e doze meninas, com idade entre oito e doze anos. As palavras sobre poesia e as palavras poéticas lidas, ouvidas, fruídas e/ou inventadas nos encontros poéticos abrem um espaço-tempo reflexivo que nos ajuda a pensar sobre algumas questões: 0 que as crianças entendem por poesia? Elas apreciam a poesia? As crianças têm um acervo poético? Quais poemas compõem o acervo infantil? Como lidamos com a poesia que as crianças nos apresentam? Como abordar a poesia com as crianças no campo da pesquisa e no espaço da escola?

A problematização e a compreensão da temática são feitas com interlocutores dos campos da linguagem, da literatura, em especial da poesia, da educação e da infância, entre os quais destacamos Bakhtin (2011), Benjamin (2002, 2013), Vigotski (2009), Paz (2012) e Kirinus (2008). Apresentamos a efervescência do espaço investigado no cenário do primeiro encontro, os diálogos e os poemas. Os fragmentos de realidade capturados pelas lentes do observador entrelaçados à interpretação deste mostram o esforço consciente para traduzir o que ouve e vê, o que encontra e o que compreende, numa prosa compartilhável que pretende dar conta não apenas de interpretar o observado, mas de fazê-lo com delicadeza.

\section{0 encontro com a poesia}

$$
\text { - O Aleph? - repeti. }
$$

- Sim, o lugar onde estão, sem se confundirem, todos os lugares do orbe, visto de todos os ângulos. A ninguém revelei minha descoberta, mas voltei. $\mathrm{O}$ menino não podia compreender que the fosse concedido esse privilégio para que o homem burilasse o poema. 
(BORGES, 1999, p. 92)

Chamamos de "encontros poéticos" as reuniões realizadas com as crianças participantes da pesquisa para ler, ouvir, inventar e fruir a poesia. Os registros desses momentos contabilizaram em torno de seis horas de gravação em vídeo, inúmeras páginas com anotações do diário de campo e material escrito produzido por elas em parceria com adultos. Sob nossa custódia estão também incontáveis imagens mentais de poemas vivos e em movimento que desfilaram em diferentes vozes. Pessoas falaram e fizeram poesia. Falaram dela e com ela. Interpretaram-na. Recolhemos um acervo não para ser guardado, mas para procurar extrair sua plurissignificação e polifonia. Uma tarefa nada fácil. Recorremos ao Aleph, de Borges (1999), para metaforizar aquele desconforto que nos assola diante da multiplicidade encontrada. Com ele, o poeta relata um mundo repleto de coisas e cores em um mesmo ponto, no qual se pode ver a aurora e a tarde, as multidões da América, uma prateada teia de aranha no centro de uma negra pirâmide, os cachos de uva, a neve, o tabaco, os veios de metal, o vapor de água... "tonto ficarás de tanto bisbilhotar onde não te chamam" (p. 94). Tarde demais... Bastou perguntarii para as crianças do que se pode fazer poesia para ouvir um dilúvio de palavras agrupadas sem a menor parcimônia e num único ponto. Para as crianças tudo está no mesmo lugar e merece a mesma atenção. Aqui estão: "Coisas bonitas, coisas emocionantes, sobre a lua, sobre o mar, sobre a natureza, sobre a riqueza, sobre viver bem, sobre bebê, sobre como falar de poesia, sobre dinheiro. Sobre vida, sobre riqueza e pobreza, sobre amor e natureza, sobre parafuso [...]".iii Podemos fazer poesia com tudo e sobre tudo. A relação entre a criança e a poesia começa com um exercício de coautoria. Uma palavra puxa outra e assim todo e qualquer ser ou objeto pode tornar-se motivo poético, em forma de brincadeira.

No poema, as palavras se (re)organizam, trocam de lugar e de sentido. "Todos os dias as palavras se entrechocam e soltam faíscas metálicas ou formam pares fosforescentes. O céu verbal se povoa incessantemente de novos astros." (PAZ, 2012, p. 42). A disposição da criança em perceber esse "faiscar" parece ser mais intensa. Ela lança um olhar inaugural numa palavra fatigada pelo uso. Diz o poeta que, dos lábios das crianças (também dos loucos, dos sábios, dos apaixonados...), brotam imagens que brilham por alguns instantes e depois se apagam. São palavras feitas de matéria inflamável que "ardem no instante em que são tocadas pela imaginação ou pela fantasia. Mas, incapazes de guardar seu fogo.” (PAZ, 2012, p. 43). Talvez a possibilidade do poético aflore nesse espaço-tempo de efemeridade, e a fugidia sensação de perda é o que nos leva a querer intensamente materializá-la, agarrá-la, preservando mais do que uma lembrança duvidosa da experiência. Então, lançamos mão da escrita. Assim nasce um poema.

\section{0 poético na roda da empiria}

Tentamos enlaçar as "faíscas" das palavras presentes no diálogo empírico e apresentá-las também na escrita dos resultados. A opção desta escrita é apresentar na íntegra a maioria dos poemas lidos, ouvidos ou criados nos encontros. Mostramos as escolhas, a maneira como emergiram, se acolhidas ou não, conjecturando sobre o que representa para adultos e crianças ler poesia num espaço-tempo que nos seduz para a virtualidade. Olhamos para esses poemas, ouvindo-os. Foram textos selecionados de forma não aleatória. Há um movimento humano que o acolheu, reconheceu a poética ali presente e o considerou possível de ser apreciado e compartilhado. Se o nosso diálogo representa uma trama entretecida por muitas vozes, as escolhas também dizem desta multiplicidade, têm nuances autorais e autobiográficas.

Pela diversidade (poética) encontrada nos caminhos investigativos não ousamos classificá-los em alguma ordem. Transcrevemo-los. Assim se reforça no exercício textual uma transgressão que a licença poética nos encorajou a utilizar, colocando no mesmo espaço consagrados e imortais poetas e 
ilustres desconhecidos. Isso não significa dizer que os poemas possam ter valor literário semelhante, obviamente. Tampouco que todos os textos lidos nos nossos encontros têm poesia, no seu sentido pleno e complexo. Mas, apenas, que na roda da empiria o mais importante era possibilitar o encontro com o universo da linguagem poética - ler, ouvir e fruir -, tomando como ponto de partida o acervo pessoal dos participantes e os textos que eles trouxessem para o encontro.

O encontro entre poesia e crianças mostrou aspectos que merecem ser tratados com criteriosa atenção. O primeiro deles diz respeito ao contato com obras, nomes e formas poéticas. Falamos de muitos poetas. Esse movimento possibilitou um diálogo fecundo e a aproximação com a poesia de nossa tradição. Foram inúmeros poemas lidos, ouvidos, interpretados, fruídos. Fragmentos de um saber que a humanidade vem entretecendo, que dá sentido e significado ao que somos ou nos tornamos num determinado contexto de inserção sociocultural. Nossas crianças têm 0 direito de conhecer os cânones e outras formas literárias não reconhecidas como tal. De serem apresentadas aos clássicos da (nossa) literatura.

Celdon Fritzen (2007, p. 10), ao problematizar o lugar do cânone na sociedade moderna, mostra como este se tornou objeto de desconfiança, por ater-se à visão de segmentos dominantes da nossa história. Contudo, o autor nos adverte que ali está materializada "uma dimensão cultural na e pela qual se pode compreender as relações entre a modernidade e a tradição e, assim, melhor se posicionar no campo de lutas da linguagem. Desconhecer a herança literária é pôr em perigo o nosso futuro." (FRITZEN, 2007, p. 10). Nesse sentido, complementa, não é uma questão de relacionar-se com o cânone numa atitude devota, mas vislumbrar em sua leitura uma promessa de liberdade, de resistência e de esperança num tempoespaço em que a cultura padece de guias, critérios e valores.

Outro aspecto a ser destacado é a forma como as crianças acolhem, a atenção que dispensam e o modo como ouvem e interagem com os textos poéticos a elas apresentados, ou por elas trazidos/mostrados - a relação estabelecida entre poesia e criança. Esse foi o objetivo maior da pesquisa: investigar a relação infância e poesia. Pensando tanto sobre o primeiro aspecto (o contato com obras, nomes e formas poéticas) quanto sobre o segundo (a forma como as crianças acolheram/acolhem, a atenção que dispensaram e o modo como interagem com os textos poéticos), fomos costurando uma singular antologia poética. Essa interação nos proporciona, além da fruição estética, o conhecimento desta e por esta forma de linguagem, tanto por sua organização estrutural, quanto por seu valor intrínseco.

O texto poético, pelo que diz e pelo modo como o faz, possibilita "gerar nos seus receptores substanciais efeitos perlocutivos" (AZEVEDO, 2002, p. 35). Ou seja, provoca o seu interlocutor a realizar atos de linguagem ativo-responsivos. A poesia explora a palavra em seu limite máximo e nos "convida" a dizer e "fazer" versos. Este aspecto linguístico (organizacional) da linguagem poética nos interessa, sobretudo quando tratamos do encontro da criança com o poeta (com a poesia) na escola, cuja função formativa lhe é inerente. Para Azevedo (2002, p. 22), compreender essa "dimensão performativa da arte e sua capacidade de geração de importantes efeitos perlocutivos supõe refletir, com detalhe, acerca da sua especificidade enquanto fenômeno estético [..., levando] em conta as suas dimensões ontológica e funcional".

O autor retoma uma das premissas mais relevantes destacadas pelos formalistas russos acerca da automatização da percepção humana e do papel renovador que a arte (poesia) exerce no processo de (des)automatização do encontro sujeitoobjeto. O movimento de Moscou, ao rejeitar a ênfase nos aspectos subjetivistas, procurou "identificar, com precisão, os códigos e os procedimentos técnicoformais que estruturam a obra de arte literária e lhe conferem a sua qualidade estética" (AZEVEDO, 2002, p. 25) e nos mostrou que, para conhecer a poesia, o que ela é, precisamos compreender como esta forma 
de linguagem funciona estruturalmente e em que se difere da linguagem cotidiana. A linguagem poética funciona de modo diferente da linguagem usual, cotidiana, pois ela:

[...] apresenta, usualmente, uma visão inabitual ou insólita da realidade, destinandose essa "deformação" e essa desarticulação intencional da monotonia da cadeia verbal linguística a melhor captar a atenção do leitor [e do ouvinte]. De facto, se a linguagem corrente se define pela promoção de um automatismo da percepção, a linguagem poética procurará, pela escolha dos elementos lexicais, pela disposição dos vocábulos, pelas associações semânticas e rítmicas, enfim, por um cuidadoso processo de selecção e de atenta estruturação do objecto estético, anular esse processo de automatização e generalização, valorizando, para o efeito, os elementos e os modos de construção que, pela sua alteridade, possam contribuir para uma incessante singularização do acto perceptivo. (AZEVEDO, 2002, p. 27)

Quando falamos da arte poética, vemos que o poema desloca o enunciado de sua função comunicativa do modo habitualmente sedimentado, sem excluí-la, para apresentá-lo num contexto renovado e plurissignificativo, que convida o leitor (ouvinte) a um olhar inaugural, fora da rotina, desfamiliarizado. Esse movimento o impele a pensar e/ou dizer algo a respeito, se faz convite à coautoria. Além disso, a interação com o texto literário se dá na esfera da ficcionalidade. Segundo Azevedo (2002), ao obedecer ao princípio da ficcionalidade, o texto literário não abre mão de uma realidade empírica histórico-factual, nem de questioná-la ou de nela intervir, mas não exige que esse movimento seja explícito, direto ou imediato. As interações ativoresponsivas de linguagem com a poesia decorrem de uma complexa atividade cognitiva que se dá no ato da leitura ou da audição por parte do receptor, num processo pautado pelo valor intrínseco da linguagem poética.

João Manuel Ribeiro (2007, p. 57) explicita o valor intrínseco e o valor instrumental da poesia. 0 poeta e pesquisador se (nos) pergunta: "Que valor tem a poesia e para que serve?" O conhecimento da literatura de modo geral, e da poesia em particular, tem valor instrumental à medida que a interação com as obras (e com seus autores) possibilita desenvolver competências de escrita, leitura e compreensão. Mas, além desse valor instrumental, a poesia possui valor em si mesma. Ribeiro (2007) reafirma a importância do valor relacional e dialógico da poesia, por estar sempre por (re)inventar realidades animadas pela imaginação dos seus interlocutores. $O$ autor destaca especialmente o valor intrínseco do texto poético: "[...] em razão de um conjunto de características específicas (como a imitação no sentido realísticoaristotélico), o ritmo, a memória, a rima e a métrica, as metáforas, a implicação do corpo e dos sentidos, o jogo e a emoção" (RIBEIRO, 2007, p. 59), cujo funcionamento axiológico está na racionalidade própria da condição humana e possibilita ao Homem dizer-se inteiro e, enquanto tal, configura-se numa representação universalizada do mundo.

Acercamo-nos de argumentos sobre as funções da linguagem poética, do seu valor intrínseco e instrumental, sem esquecer que o valor da poesia também está em sua aparente despretensão. A palavra poética explora diferentes sentidos, entra e sai do espaço real e do ficcional sem aviso prévio. A palavra do poeta mexe com o tempo, com o espaço. O tempo poético se revigora. A poesia "recupera a temporalidade e o sentido da transmissão do próprio texto como testemunho humano fundamental" (RIBEIRO, 2007, p. 59). No encontro com o poeta, a admiração não está no seu ser, mas na poesia que ele incorpora e representa. Ao olharmos o homem, enxergamos o poético. Ambos nos envolvem com os legados de uma memória coletiva, viva e em permanente recriação.

O encontro com o poeta nos ajuda a enxergar os vários sentidos que uma palavra pode assumir. Vemos os poemas "desfilarem" e os ouvimos com um tempo dedicado exclusivamente a eles, provocando o que Kirinus (2008, p. 50-51, grifo do autor) chama de "estado poético da criança e do adulto [e este] tem muito de imprestável, muito de domingo [...]. Estar aberto, domingueiramente, para o mundo significa também estar receptivo para a poesia. Significa saber respirar a ambiência e interpretá-la com toda a originalidade do ser." Com a 
aproximação da poesia no encontro com o poeta, procuramos não traí-la. Por isso, ainda que confabulando sobre questões cruciais acerca da logística que envolve a visita de um escritor (poeta) na escola, a ênfase reflexiva recai sobre o aspecto metafórico e subjetivo da experiência, repercutindo as vozes originárias de distintas fontes.

\section{0 "primeiro" encontro: diálogos e efervescências}

E é sempre o mesmo chão, / a mesma poeira nos versos, / a mesma peneira separando os grãos, / a mesma infância nos devolvendo a palavra/ a mesma palavra devolvendo a infância. // E assim, / sem lonjura, / na mesma água / riscaremos a palavra / que incendeia a nuvem.

(COUTO, 2013, [s. p.])

- Meu nome é Cauã.

- Meu nome é Maiara e eu sempre gostei de poesia!

- Meu nome é Vanessaiv, adoro poesia. Quero ser poeta.

- Eu sou o Samuel, amo poesias. Quero ser poeta.

- Meu nome é Dionatanv, estou no quarto ano, adoro poesia e quando crescer quero ser um poeta.

- Sou Cailane e gosto muito de poesia!

- Meu nome é Hugo, estou no terceiro ano e gosto de poesia.

- Meu nome é Geovani, estou na [turma] 501, quinto ano, e adoro ler e fazer poesia. ${ }^{\mathrm{vi}}$

A proposição era apresentar-se da maneira que quisesse. Depois de uma apresentação nominal acompanhada de espontâneas "declarações de amor" à poesia, a conversa prosseguiu:

- Vocês sabem quem é que fez aniversário no sábado? (SILVEIRA, 2013b, 10s)

- A professora? (HOFFMANvii, 2013, 19s)

- Não! Tinha alguém fazendo cem anos no sábado, quem será? (SILVEIRA, 2013b, 20s)

- Ah, já sei, um poeta, mas esqueci do nome dele. (URBANO, 2013, 26s)

- Se estivesse vivo ele estaria fazendo cem anos, quem é? (SILVEIRA, 2013b, 28s)

- A gente viu ele. Eu sei, você levou ele na nossa sala. [pensando...] Esqueci o nome dele. (URBANO, 2013, 30s)

- Não. Aquele não tem cem anos, ainda. (SILVEIRA, 2013b, 35s)

- Ai, eu sei, mas esqueci do nome dele... Até na Globo falaram dele, no Esporte Espetacular. Eu vi domingo. (URBANO, 2013, 38s)
- Quem é? Já que vocês não lembram, posso contar então quem estava fazendo aniversário no sábado? (SILVEIRA, 2013b, 42s) 2013, 1 min52s

- Não! Deixa a gente adivinhar! (BONETTI,

- O poeta que estava fazendo aniversário no sábado chama-se... [mostrando um livro, como uma pista]. (SILVEIRA, 2013b, 1min54s)

- Ah! Vinicius de Moraes! (BONETTI, 2013, $1 \min 55 \mathrm{~s})$

- Vinicius! (HOFFMAN, 2013, 1min58s)

- Sabia que era ele! O Vinicius de Moraes. (URBANO, 2013, 2min)

- Eeeee! (Crianças juntas, vibrando)

- Ele já morreu? Morreu, "sôra"? (MONTEIRO, 2013, 2min6s)

- Então, já faz tempo! Mas deixou uma obra enorme! (SILVEIRA, 2013b, 2min8s)

Falar de Vinicius, poeta brasileiro que nasceu em 19 de outubro de 1913 e faleceu em 9 de julho de 1980, no Rio de Janeiro, autor de diversos poemas para adultos e crianças, foi um modo de iniciar o diálogo de forma que pudesse interessar aos interlocutores e também marcar os motivos maiores do nosso encontro: poesia, poemas, poetas. Vinicius de Moraes é um escritor conhecido pelas crianças desta escola por alguns de seus poemas viii. Foi badalado pela mídia popular por ocasião do centenário de seu nascimento. Tem muitos poemas direcionados aos pequenos. No gênero infantil, criou um zoológico poético que encanta as crianças, fazendo dos animais seus motivos preferidos de composição. Colocou "O gato", "O elefantinho", "O leão", "O pato", “As borboletas”, "O marimbondo", "As abelhas" e outros bichos de todos os tamanhos no seu livro A Arca de Noé (MORAES, 2004).

Este foi o primeiro dos encontros, no qual era preciso consolidar a parceria. A proposta metodológica adotada requer a disposição para uma escuta sensível do que dizem as crianças e ocupar-se dos sentidos que estes sujeitos vão trazer, ainda que estes, em muitos momentos, possam nos causar rejeição. Podemos qualificar as primeiras ações junto às crianças como estratégias de conquista porque, de fato, aqui somente interessa a participação voluntária da criança. Leite (2008) discorre sobre esta questão como uma das formas de minimizar as relações de poder entre adultos e crianças. Estamos falando de um evento que ocorre de forma extracurricular, no qual as crianças precisam empreender um esforço a 
mais para vir à escola novamente, uma vez que tiveram um período de aula pela manhã. Evento em que elas não têm nenhuma obrigação de participar, que não vai "valer nota"... Que elas podem desistir a qualquer momento.

Tratando um pouco mais sobre a participação voluntária na pesquisa, Leite (2008) explica que os "espaços de narrativa" são pensados para dialogar com:

\begin{abstract}
[...] crianças variadas que queiram participar. Entendemos que a obrigatoriedade já inviabilizaria esta proposta do jeito como vem sendo estruturada. Se as relações de poder são inegáveis (e reconhecidamente inevitáveis), as ações junto às crianças, devem ser, logo de início, pelo menos centrada na opção, no desejo, no querer participar por parte delas. Pesquisar crianças sem que estas assim o desejem é manter uma estrutura de poder e distanciamento que não as emancipa do papel de objeto de estudo; que as mantém sob a égide do adultoque-manda versus a criança-que-obedece. Portanto, centrar-se no querer da criança, por si só, já marca uma mudança nas relações social e culturalmente estabelecidas entre adulto-criança na contemporaneidade. (LEITE, 2008, p. 123)
\end{abstract}

A pesquisa levou em conta o aspecto voluntário de participação e se pautou em negociações e gentilezas entre adultos e crianças.

Se, por um lado, o observador adulto quer conquistar a criança e tê-la como parceira; por outro, a fala inicial dos meninos e meninas procurou marcar um discurso favorável ao objeto em estudo para, com isso, serem aceitos no grupo e garantir sua permanência. A apresentação das crianças complementada por enunciados apreciativos do tipo "eu sempre gostei de poesia”, “adoro poesia”, “amo poesias", "quando crescer quero ser um poeta", "gosto muito de poesia!" foram declarações estratégicas que anunciavam o potencial de contribuição que elas acreditavam possuir e estavam oferecendo, generosa e gratuitamente. O Dionatan inseriu a irmã Maria Vitória $^{i x}$ no grupo em 2014; a Ana Júlia ${ }^{x}$ chegou à escola no início de 2014, soube dos encontros pela Cailane e solicitou sua inserção no grupo argumentando que precisava participar dos encontros, pois quando crescer vai ser escritora; a
Hérika ${ }^{x i}$ não conseguindo a autorização inicial, insistiu para que a mãe fosse até a escola para autorizá-la a participar dos encontros. Estas e outras atitudes das crianças durante o percurso investigativo também demonstraram não apenas o querer fazer parte do grupo como também um valor atribuído, tanto à experiência proposta (encontros poéticos) quanto ao tema em estudo (a poesia).

\section{Os "primeiros" poemas compartilhados}

[...] / Varre, varre vassourinha, / Varre o preto e mostra a lua, / Varre a noite, limpa a estrela, / Poesia ninguém segura!

(ORTHOF, 2005, p. 6)

O cenário que acolheu o primeiro encontro poético era composto de muitos livros. Livros de poemas, evidentemente. Encontramo-nos para ler, ouvir, inventar e fruir a poesia. Fomos buscá-la nos livros. Em poucos instantes, cada criança estava folheando um deles a procura de um poema que pudesse ser lido. $\mathrm{Na}$ sequência, abaixo, são apresentados alguns dos poemas compartilhados no encontro. Alguns escolhidos pelas crianças, ali mesmo, naquele "espaço de narrativa", a partir do que a mesa oferecia. Outros, do mesmo acervo, foram selecionados previamente, com base em experiências anteriores de mediação da leitura poética com as crianças.

Geovani Hoffman (2013, 8min54s) se apressou em selecionar e ler "Barriga cheia", escrito por José Paulo Paes, e "Hai-kal", de Mario Quintana. Além da leitura, ele mostrou ao grupo a ilustração do livro, no que Samuel Monteiro (2013, 9min25s), o nosso "cinegrafista amador"xii, reivindicou: "mostra aqui para a câmera!".

\section{Barriga cheia}

Olha lá / o tamanduá / tomando ar! // Sua língua comprida / entra feito lombriga / no formigueiro / para comer formiga. // Olha lá, olha lá! / quem disse que formiga / não enche barriga / de tamanduá?

José Paulo Paes

(PAES, 2002, p. 10)

Hai-kai 
Em meio da ossaria / Uma caveira piscava-me / Havia um vagalume dentro dela.

Mario Quintana

(QUINTANA, 2002, p. 11)

O menino (HOFFMAN, 2013, 9min40s) não resiste. Ao escolher um poema para ler e perceber outro na página ao lado, ele (pre)sentiu que este outro também precisava ser lido. Na sala de aula, quando estamos com um livro de poemas nas mãos para ler para as crianças, ao terminar a leitura daquele escolhido, elas necessariamente pedirão: "Leia mais um, mais um!". É prudente estarmos preparados. Também o menino leu o primeiro e ficou em prontidão. "Você vai ler o outro também?" perguntamos. Ele faz um gesto afirmativo com a cabeça e lê o "Hai-kai". Ele continua com o livro nas mãos (folheia), prosseguindo em sua busca. Para Bocheco (2002, p. 22), isso acontece porque 0 "universo da poesia é caro à criança; é um reino de sua intimidade onde ela pode recolher alpiste pro sonho, enriquecendo-se e elaborando vivências".

"O meu celular", poema escrito por Cauã, está guardado no livro Amigos da poesia (SILVEIRA, 2013a, p. 7) e foi escolhido por Hugo Bonetti (2013, 10min7s) para leitura no grupo. A escolha enalteceu 0 menino-autor ali presente, que não disfarçou sua satisfação. No encontro deste dia de primavera, ainda lemos e ouvimos mais cinco poemas produzidos por crianças, alunas desta escola.

Passamos o restante do nosso tempo dedicando-nos a procurar e a encontrar, a ler e a compartilhar poemas a partir daquele pequeno universo ali disponível. Dos poemas lidos, alguns foram mais comentados, outros menos. Alguns ouvidos com maior atenção, outros nem tanto. Mas todos mereceram o foco da câmera e as palmas das crianças. "Infinito amor", de Sylvia Orthof, foi escolhido por Vanessa de Jesus (2013, 21min50s). Ouvimos uma vez, duas, depois brincamos num jogo de vozes. A menina lia em voz alta e nós repetíamos:

Infinito amor

Vamos / brincar / de / amor? / Eu / te / amo, / tu / me / amas... / - Pra sempre? / - Por / três / semanas!
Sylvia Orthof

(ORTHOF, 2005, p. 11)

Esse poema favorece a brincadeira, é um convite para brincar de amor. O tempo foge da contagem convencional e o menino repete para confirmar que "pra sempre" pode ser "por três semanas, [...] só por três semanas mesmo" (MONTEIRO, 2013, 22min9s).

Este mesmo menino, o Samuel (MONTEIRO, 2013, 24min2s), por sua vez, escolheu dois haikais presentes em Conversa de passarinhos, livro escrito por Alice Ruiz S. e Maria Valeria Rezende, publicado em 2008, que fez parte do acervo do Programa Nacional Biblioteca da Escola - PNBE (2010), enviado às escolas públicas. Nesse livro, as autoras fazem uma espécie de pingue-pongue poético em cada uma das páginas. Entre a página treze e a setenta e três, Ruiz faz o primeiro poema e Rezende o segundo, identificando a autoria com as iniciais de seus nomes. O livro também traz informações sobre esta forma poética. Ruiz (2008, p. 9) informa aos leitores que o "haikai se faz com três linhas, ou versos, e não mais que 17 sílabas. Seu tema é a natureza, e não os nossos sentimentos e pensamentos." O menino espera a atenção do grupo para fazer a leitura. Faz com a voz cadenciada e finaliza a leitura com um suave sorriso.

Fim de tarde / Sino de vento acompanha / O canto dos pássaros

Alice Ruiz

(RUIZ; REZENDE, 2008, p. 27)

Canta o concriz / Nem alegre nem triste /

Apenas canto

Maria Valéria Rezende

(RUIZ; REZENDE, 2008, p. 27)

"Natureza" foi outro poema selecionado e lido pelo Hugo (BONETTI, 2013, 27min12s), e "Epitáfio do jardineiro" foi escolhido pela Maiara Urbano (2013b, 4min7s), ambos escritos por João Marino Vieira (2007). Explicamos ao grupo que os livros do poeta foram trazidos para que pudéssemos conhecer seus poemas, uma vez que esse escritor aceitou participar 
dos nossos encontros. Assim, teríamos a oportunidade de conversar com ele, conhecê-lo pessoalmente e fazer perguntas. $O$ grupo se mostrou animado com o anúncio e quis saber se os demais autores também poderiam vir.

Natureza
Senhora Dona / deixa eu entrar / em seu
coração / deixa eu ficar // Senhora, / dona do
espaço estrelar / estrela da noite / do meu
despertar // Senhora, / dona do azul do mar /
estrela na terra / luz a encadear // Senhora, /
dona de todo lugar / vestida de versos / pra se
revelar
João Marino Vieira
(VIEIRA, 2007, p. 41)
Epitáfio do jardineiro

Não me cortem flores, / Cuidei que crescessem, / Não as quero agonizantes, / Definhando sobre meu peito.

João Marino Vieira

(VIEIRA, 2007, p. 74)

Maiara (URBANO, 2013, 31min8s) escolheu Casimiro de Abreu (2003). Ela leu apenas a primeira estrofe de Meus oito anos. A pesquisadora se ofereceu para fazer a leitura na íntegra, mostrou as ilustrações que acompanham o livro. Procurou dar uma entonação de voz vibrante, que pudesse carregar aqueles meninos e meninas até a paisagem do poema. As crianças ouviram num silêncio murmurante. $O$ caráter afetivo dessa paisagem acariciou cada um deles. Ao ler o último verso, "debaixo dos laranjais", escutou-se um sonoro “uuuuiiiia!".

Kirinus (2011, p. 33) afirma que a "infância é hiperbólica por natureza. Ela amplia e aumenta, com a lente da fantasia, do mundo fabuloso, o tempo e o espaço que lhe toca viver. O tempo é sempre agora." A criança é transportada imaginativamente para o tempo-espaço do agora narrado pelo poema. A expressão verbalizada "uuuuiiiia", quase como um grito, marca a chegada do menino a esse cenário poético. Sem identificar o autor da expressão, ela cabe a cada ouvinte daquela clareira. A singularidade da criança que se entrega inteira à experiência remonta ao texto "Esconderijos", narrado por Benjamin (2013, p. 103): quando a criança está escondida "atrás de uma porta ela própria é porta, recoberta por ela, máscara pesada, mago que enfeitiçará todos os que entrarem desprevenidos". E com um grito forte ela expulsa o demônio em que se transforma quando é agarrada por aquele que a está procurando. Nem espera ser encontrada, mas vai ao encontro de quem a procura, com um grito de autolibertação.

Geovani (HOFFMAN, 2013, 3min10s) escolheu ler e compartilhar "As folhinhas de hortelã", de Carlos Luis Sáenz:

As folhinhas de hortelã

As folhinhas frescas / da hortelã / com lua e estrelas. / Eram as amigas / Do regador, / Dos vaga-lumes / E das borboletas. / Conheciam as mãos / secas da vovó; / conheciam as horas / de sombra serena / e eram muito felizes / com a lua nova. / As folhinhas frescas / da hortelã, / com lua e estrelas...

Carlos Luis Sáenz

(SÁENZ, 2008, p. 30)

A "Natureza", o "Epitáfio do jardineiro" e "As folhinhas de hortelã" são poemas que nos aproximam da natureza, nos ajudam a colocar o pé no chão e a respirar a atmosfera que emana da terra fresca, como parte de nossa própria existência. As crianças quiseram conhecê-los. Será que elas se sentem atraídas por textos em que a natureza viva e vibrante se faça presente e possa brincar com elas? Kirinus (2011, p. 34) cita Manoel de Barros e seu poema que trata de um "mundo [que] não foi feito em alfabeto, mas em água, terra e até em lagartixa", e confirma que a: "Natureza do conhecimento e a natureza do mundo chegam juntas para todos nós" (KIRINUS, 2011, p. 34). Por que então vamos separá-las? Antes de finalizar 0 encontro daquela tarde fagueira, pudemos ler, ouvir e fruir o "Vassoural", de Sylvia Orthof (2005, p. 6), na voz apressada do Samuel (MONTEIRO, 2013, 33s).

\section{Considerações}

O diálogo com as crianças nos forneceu indicativos de que a relação entre a infância e a poesia pode ser bastante promissora. Meninos e meninas se mostram disponíveis e dispostos a lidar 
lúdica, afetiva e imaginativamente com a poesia. Quisemos saber: a criança faz poesia? Trabalhamos com a hipótese de que a criação de poemas e a composição brincante com palavras pode ser uma experiência relevante para a criança no sentido de comunicar em palavras suas percepções e a imaginação criadora. Pautamo-nos em Vigotski (2009) para entender que a imaginação, como a base da atividade criadora, se manifesta nos diferentes aspectos da vida cultural e impulsiona a criação artística, técnica ou científica. Ao enfatizarmos a autoria no encontro poesia e criança estamos pensando numa estratégia dinâmica de aproximação entre o texto poético, sua forma e conteúdo, e o leitor que se coloca na condição de autor, que brinca de ser poeta. Cunha (2012, p. 118) afirma que mesmo antes do "pleno domínio do código alfabético, as crianças são capazes de ler e escrever poemas". Esta criação começa com o ato de ouvir, ler e fruir o poema de maneira autoral e imaginativa.

Destacamos aqui as vivências do primeiro encontro poético que, por sua vez, marcou um passo importante para a empiria e para a pesquisa como um todo. Naquele dia lemos e ouvimos vários e belos poemas. Belos porque acolhidos e aplaudidos por crianças que vieram ao encontro querendo a poesia, "que tem um monte de rima"xiii e muitas "palavras bonitas". Elas terão que voltar, pois "tem bastantes poesias diferentes, que eu achei muito interessante"xiv. Bocheco (2002, p. 14) afirma, com base na própria experiência, "que é muito raro uma criança descobrir a poesia e não se encantar". Elas prometeram voltar. Perguntamos se poderiam e queriam trazer algum poema que encontrassem no caminho e a resposta também foi afirmativa. Tínhamos dado juntos um grande passo para ir ao encontro da poesia. Isso nos possibilitou tratar de aspectos que envolvem a questão tanto nos vieses teórico e metafórico, quanto como ação prática de mediar a relação poesia e criança (na escola e para além dela), refletindo sobre os possíveis desdobramentos e aprendizados que essa experiência pode propiciar.

\section{Referências:}

ABREU, Casimiro de. Meus oito anos. llustrações de Fê. São Paulo: Global, 2003.

AZEVEDO, Fernando José Fraga de. Texto literário e ensino da língua: a escrita surrealista de Mario Cesariny. Braga Centro de Estudos Humanísticos: Universidade do Minho, 2002.

BAKHTIN, Mikhail. Estética da criação verbal. 6. ed. Tradução de Paulo Bezerra. São Paulo: Martins Fontes, 2011.

BENJAMIN, Walter. Infância Berlinense: 1900. In: Obras escolhidas II - Rua de mão única.

Tradução de João Barrento. Belo Horizonte:

Autêntica, 2013. p. 67-116.

Reflexões sobre a criança, o brinquedo e a

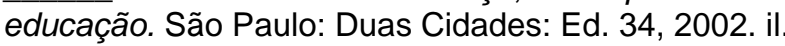

BOCHECO, Eloí Elisabet. Poesia Infantil: o abraço mágico. Chapecó: Argos, 2002.

BONETTI, Hugo Bonfanti. Encontro poético. [21 out. 2013]. Pesquisadora: Rosilene de Fátima Koscianski da Silveira. Criciúma, 2013. 1 arquivo de audiovisual (gravação em vídeo: MOV000981, 32min7s).

BORGES, Jorge Luís. O Aleph. Tradução de Flávio José Cardoso. São Paulo: Globo, 1999.

COUTO, Mia. Um abraço para Manoel. 19 dez. 2013. In: CONTI, Josie. Conti outra. Blog. Disponível em: <http://www.contioutra.com/o-poema-que-mia-coutoescreveu-para-manoel-de-barros/>. Acesso em: 13 abr. 2015

CUNHA, Maria Zilda. Poesia. In: GERGORIN FILHO, José Nicolau. (Org.). Literatura infantil em gêneros. São Paulo: Mundo Mirim, 2012. p. 104-122.

FIGUEREDO, Rafaela Redivo de. Encontro poético. [25 nov. 2013]. Pesquisadora: Rosilene de Fátima Koscianski da Silveira. Criciúma, 2013. 1 arquivo de audiovisual (gravação em vídeo: MOV01030, 9min57s).

FRITZEN, Celdon. O lugar do cânone no letramento literário. In: REUNIÃO ANUAL DA ASSOCIAÇÃO NACIONAL DE PÓS-GRADUAÇÃO E PESQUISA EM EDUCAÇÃO, 30, 2007, Caxambu. Anais... Caxambu: ANPED, 2007. Disponível em:

$<$ http://30reuniao.anped.org.br/trabalhos/GT10-3679Int.pdf>. Acesso em: 6 nov. 2006.

HOFFMAN, Geovani Ivtes. Encontro poético. [21 out. 2013]. Pesquisadora: Rosilene de Fátima Koscianski da Silveira. Criciúma, 2013. 1 arquivo de audiovisual (gravação em vídeo: MOV00981, 32min7s).

JESUS, Vanessa Nunes de. Encontro poético. [21 out. 2013]. Pesquisadora: Rosilene de Fátima Koscianski da Silveira. Criciúma, 2013. 1 arquivo de 
audiovisual (gravação em vídeo: MOV00981, $32 \min 7 s)$.

KIRINUS, Glória. Criança e poesia na Pedagogia Freinet. 3. ed. São Paulo: Paulinas, 2008.

Synthomas de poesia na infância. São Paulo: Paulinas, 2011.

KRAMER, Sônia. Autoria e autorização: questões éticas na pesquisa com crianças. Cadernos de Pesquisa, São Paulo, n. 116, p. 41-59, jul. 2002.

LEITE, Maria Isabel. Espaços de Narrativa - onde o eu e o outro marcam encontro. In: CRUZ, Silvia Helena Vieira. (Org.). A criança fala: a escuta de crianças em pesquisas. São Paulo: Cortez, 2008. p. 118-140.

MONTEIRO, Samuel da Silva. Encontro poético. [21 out. 2013]. Pesquisadora: Rosilene de Fátima Koscianski da Silveira. Criciúma, 2013. 1 arquivo de audiovisual (gravação em vídeo: MOV000981, 32min7s).

MORAES, Vinicius. A arca de Noé. llustrações de Nelson Cruz. São Paulo: Companhia das letrinhas, 2004.

MORAES, Ana Júlia Rodrigues. Encontro poético. [3 abr. 2014]. Pesquisadora: Rosilene de Fátima Koscianski da Silveira. Criciúma, 2014. 1 arquivo de audiovisual (gravação em vídeo: MOV1132, 32min7s)

ORTHOF, Sylvia. A poesia é uma pulga. Ilustrações de José Flávio Teixeira. São Paulo: Saraiva, 2005.

PAES, José Paulo. Barriga cheia. In: MEIRELES, Cecília. et al. Varal de poesias. Ilustrações de Alex Cerveny. São Paulo: Ática, 2002. p. 10.

PAZ, Octávio. O arco e a lira. Tradução de Ari Ritman e Paulina Wacht. 2. ed. São Paulo: Cosac Naify, 2012.

QUINTANA, Mario. Hai-kai. In: MEIRELES, Cecília. et al. Varal de poesias. Ilustrações de Alex Cerveny. São Paulo: Ática, 2002. p. 11.

RIBEIRO, João Manuel. O valor pedagógico da poesia. Revista Portuguesa de Pedagogia, Coimbra, ano 41, n. 2, p. 51-81, 2007. Disponível em: $<$ http://impactum-

journals.uc.pt/index.php/rppedagogia/article/viewFile/1 196/644>. Acesso em: 3 nov. 2016.

RUIZ, Alice; REZENDE, Maria Valéria. Conversa de passarinho: haikais para crianças de todas as idades. Ilustrações de Fê. São Paulo: Iluminuras, 2008.

SÁENZ, Carlos Luis. As folhinhas da hortelã. In: MORVILLO, Mabel (Org.). Poemas com sol e sons: poesia latino-americana para meninas e 345 meninos. Tradução de Yolanda Serrano Meana. Ilustrações de Vicky Ramos. São Paulo: Melhoramentos, 2008.
SARMENTO, Manuel Jacinto. O estudo de caso etnográfico na educação. In: ZAGO, Nadir; CARVALHO, Marilia Pinto de; VILELA, Rita Amélia Teixeira. (Orgs.). Itinerários da pesquisa: perspectivas qualitativas em sociologia da educação. 2. ed. Rio de Janeiro: Lamparina, 2011. p. 137-179.

SILVA, Dionatan Mateus da. Encontro poético. [21 out. 2013a]. Pesquisadora: Rosilene de Fátima Koscianski da Silveira. Criciúma, 2013. 1 arquivo de audiovisual (gravação em vídeo: MOV00981, 32min7s)

SILVEIRA, Rosilene de Fátima Koscianski da (Org.). Amigos da poesia. Criciúma, 2013a. Exemplar único, editado artesanalmente.

Encontro poético. [21 out. 2013]

Pesquisadora: Rosilene de Fátima Koscianski da Silveira. Criciúma, 2013b. 1 arquivo de audiovisual (gravação em vídeo: MOV00981, 32min7s).

VIEIRA, João Marino. O jardineiro: poesias de amor à terra. Criciúma: Edição do autor, 2007.

VIGOTSKI, Lev Semenovich. Imaginação e criação na infância: ensaio psicológico. Apresentação e comentários de Ana Luiza Smolka. Tradução de Zoia Prestes. São Paulo: Ática, 2009.

URBANO, Maiara Manoel. Encontro poético. [21 out. 2013]. Pesquisadora: Rosilene de Fátima Koscianski da Silveira. Criciúma, 2013. 1 arquivo de audiovisual (gravação em vídeo: M

\footnotetext{
' A pesquisa foi financiada pelo Programa do Fundo de Apoio à Manutenção e ao Desenvolvimento da Educação Superior (FUMDES/UNIEDU); e o Estágio Científico Avançado (Doutorado Sanduíche) pela Coordenação de Aperfeiçoamento de Pessoal de Nível Superior (CAPES).
}

ii A pergunta foi feita às crianças tanto oralmente quanto por escrito no primeiro encontro, dia 21 de outubro de 2013, e retomada no segundo, em 4 de novembro de 2013, e em outros momentos, eventualmente.

iii Maiara Manoel Urbano. "Meu nome é Maiara, tenho onze anos. Meu aniversário é dia 29 de setembro. Gosto de poesias. Adoro que os poetas venham na escola e espero que eles não parem de vir." As crianças são identificadas com seus nomes próprios em função da autorização concedida por elas e por seus responsáveis legais; de suas falas/escritas não apresentarem riscos de qualquer natureza ao se tornarem públicas; e, como forma efetiva de reconhecimento da autoria. Sobre isso ver Kramer (2002)

iv Vanessa Aparecida Nunes de Jesus. "Meu nome é Vanessa. Tenho onze anos. Eu aprendi várias coisas 
de poesia e quero aprender mais. Tenho poesias e vou ter mais. Eu amo poesias."

$\checkmark$ Dionatan Mateus da Silva. "Menino - play Facebook - gosto de poemas."

vi Apresentação das crianças na gravação em vídeo MOV00980, 2min18s, em 21 out. 2013.

vii Geovani Ivtes Hoffman. "Sou um menino de dez anos. Estudioso? Mais ou menos, só estudei nesta escola este ano. Moro bem perto da escola e venho com meu irmão para a escola. Não tenho Facebook, mas gostaria de ter computador em casa com internet. Gosto de estudar e jogar - meu jogo preferido é o de motos. Nunca procurei poesia na internet, vou procurar agora."

viii "As abelhas", "O gato" e "O pato [pateta]" foram alguns dos poemas citados pelas crianças (anotações no diário de campo, em 21 out. 2013).

ix Maria Vitória Mateus da Silva. "Tenho oito anos, me acho uma menina inteligente que gosta de brincar com as meninas do quarto e do quinto ano. Moro longe da escola e por isso minha mãe vai me transferir para outra escola. Gosto muito de poesia poesia para mim é coisa importante."

× Ana Júlia Rodrigues Moraes. "Estudo no quarto ano. Em 2014 eu pedi para entrar na pesquisa porque quero ser escritora. Quero muito fazer um livro. Gosto de fazer poesias e entro na internet para fazer pesquisa. Gosto de brincar de pega-pega, escondeesconde. Moro com meu pai."

xi Hérika Abigail Oliveira Machado. "Sou Hérika gosto de jogar no computador e mexer no Face, onde tenho muitos amigos. Tenho dois cachorros. Tenho doze anos. Gosto de limpar a casa, moro longe da escola, mas faço o possível e o impossível para chegar na hora certa. Gosto bastante dos meus professores desta escola. Gostei do poema do parafuso e de um poema que a Rafa trouxe para o encontro que falava sobre amizade."

xii Falando do cinegrafista, em relação à gravação em vídeo, a opção encontrada foi colocar na mão das crianças a pequena e discreta máquina fotográfica, com a qual fizemos a filmagem, em quatro encontros. Depois foi usada a câmera do computador. A ideia era que esse instrumento de captura, tão importante para a pesquisa, não se tornasse 0 centro das atenções. De mão em mão, cada criança filmava uma parte do encontro, como se estivesse brincando. Houve disputa para assumir a função e observou-se 0 modo como elas direcionaram o foco para a leitura/os leitores dos poemas.

xiii Letícia de Souza Simão. "Me chamo Letícia, tenho nove anos de idade, as coisas que eu mais gosto são poesia, internet, escrever, ler, sair, me divertir."

xiv Cauã Medeiros da Silva. Encontro poético de 4 nov. 2013.
SILVEIRA, Rosilene de Fátima Konscianski da: DEBUS, Eliane Santana Dias; AZEVEDO, Fernando José Fraga de. A LINGUAGEM POÉTICA EA CRIANÇA: OUVIR, LER, CRIAR, FRUIRE BRINCAR. Signo. Santa Cruz doSul,

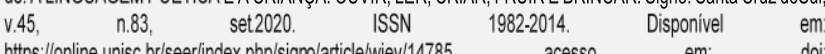
https://online.unisc.br/seer/index.pho/signo/article/wiev/14785, acesso en: https://foi.org/1017058//signo.v45i83.14785 